\title{
Fore reef location influences spawning success and egg predation in lek-like mating territories of the bird wrasse, Gomphosus varius
}

\author{
A. M. Gill (1D • E. C. Franklin • T. J. Donaldson
}

Received: 28 October 2020 / Accepted: 16 March 2021 / Published online: 2 April 2021

(C) The Author(s) 2021

\begin{abstract}
Many fish spawn in aggregations, but little is understood about the dynamics governing the success of spawning interactions. Here, we evaluate the influence that location of lek-like mating territories has on spawning interactions of Gomphosus varius. We used direct observations of spawning and egg predation events as well as local population counts to compare the rates of spawning, spawning interruptions, and predation on the eggs of G. varius at Finger Reef, Apra Harbor, Guam. We hypothesized that spawning rates would be highest among seaward locations that facilitate transport of pelagic larvae from reefs and that those territories would subsequently experience higher densities of egg predators, egg predation rates, and spawning interruptions. Male spawning success was highly skewed by mating territory location, with holders of the outer, seaward mating territories being more successful than those males holding territories in the middle and inner areas of the aggregation site. Within the outer territories, male mating success was also skewed by location. Egg predation was observed occasionally and increased linearly with bird wrasse spawning frequency. The population densities of egg predators were distributed equally across the study area. Spawning interruptions
\end{abstract}

\footnotetext{
A. M. Gill $(\bowtie) \cdot$ T. J. Donaldson

Marine Laboratory, University of Guam, Mangilao, GU, USA e-mail: gillalisha10@gmail.com

E. C. Franklin

Hawaii Institute of Marine Biology, School of Ocean and Earth Science and Technology, University of Hawaii at Manoa, Kaneohe, HI, USA
}

occurred most frequently within the inner zone of the spawning aggregation due to greater male-male aggression in intraspecific competition for females and territories. This study provides evidence that reef location influences the spawning success, egg predation rates, and spawning interruption rates of fishes that reproduce using lek-like mating territories.

Keywords Guam · Courtship · Hurdle models . Predation · Spawning aggregation $\cdot$ Reproductive behavior

\section{Introduction}

The behaviors associated with spawning play an important role in the survival of fish and their offspring (Hunter 1981). Spawning is a time of increased vulnerability for fish that often draws the attention of predators since recently spawned eggs are a common food item for many planktivores (Robertson and Hoffman 1977). Prior observations of spawning fish have noted the presence of planktivores, however, egg predation rates greatly vary across locations and species (Johannes 1978; Colin and Clavijo 1988; Colin and Bell 1991; Claydon 2004). In general, spawning by many fish species is thought to occur at times and locations that reduce the chance of predation, increase chances of egg dispersal, and increase the success of larval survival and settlement (Claydon 2004; Molloy et al. 2012). Even so, many species spawn during daylight and therefore, must rely upon other biotic or abiotic factors that discourage 
egg predation and promote egg dispersal. For example, many fish species spawn in areas where eggs have the best chance of being carried away from predators by currents, such as near channels, at the edge of a reef, during prime tidal conditions, and at depths high enough above the substrate to prevent non-swimming predators from reaching their eggs (Robertson and Hoffman 1977; Thresher 1984; Claydon 2004). To increase reproductive success, spawning usually occurs in areas with optimal current, during prime tidal conditions, and at depths high enough above the substrate to prevent nonswimming predators from reaching their eggs such as on the edges of reefs (Thresher 1984; Claydon 2004).

Spawning aggregations occur when a group of fish of the same species gather for the purpose of spawning. Spawning aggregations can be divided into two groups; transient and resident. Transient spawning aggregations are typically formed by larger pelagic or reef species and may involve a long migration of days to weeks to reach the spawning aggregation site. Resident spawning aggregations are usually formed by smaller reef species (although some much larger species form them as well) and occur within the home ranges of the individuals involved (Domeier and Colin 1997). Transient aggregations, typical of many fishery species such as groupers and snappers, form seasonally and are usually linked to a lunar cycle (Domeier 2012). Various other species form resident aggregations that may not have seasonality at low latitudes, are not necessarily linked to a lunar cycle, and may form every day (Domeier and Colin 1997). The dynamics of spawning aggregations are not well understood; how, why, and when they are formed can be explained by many factors (Domeier and Colin 1997). Many commercially important fish species spawn in aggregations, thus, there are ecological, evolutionary, and economic motivations to better understand this important phenomenon (Domeier 2012). Unfortunately, unfished, and thus fully functional spawning aggregations of many commercially important species may often occur at unknown locations or areas that are difficult to reach (Sadovy de Mitcheson et al. 2008). The wrasses (family Labridae) have a considerable number of species that form spawning aggregations (Claydon 2004).

To increase our understanding of fish spawning aggregations, we examine the intra- and interspecific interactions of the bird wrasse, Gomphosus varius Lacepede 1801, which form resident spawning aggregations as temporary courtship territories using a lek- like mating system (Desvignes et al. 2017) and spawn in semilunar cycles (Kuwamura et al. 2016). We propose that locations of the fore reef from seaward to shoreline will influence spawning interactions and egg predation by planktivorous fishes on spawned gametes. Using resident $G$. various courtship territories at Finger Reef, Guam, we compare spawning rates, spawning interruptions rates, and predation rates on the eggs of $G$. varius across the fore reef zone. A lek-like system is characterized by female mate choice. In this system, males defend a temporary spawning territory, which may stand alone or be within a spawning aggregation site to which females migrate (Loiselle and Barlow 1978; Donaldson 1990; Chop 2008). These females then choose a male to spawn with and leave after spawning (Moyer and Yogo 1982; Colin and Bell 1991; Gladstone 1994; Molloy et al. 2012). The mating territories in this aggregation can be separated into three distinct categories based on their locations across the fore reef zone within the aggregation: outer, middle, and inner. The outer territories are in the deepest water and are the most seaward, located on the reef's edge. The inner territories are the shallowest and are closest to the shore. The middle territories are located in between the outer and inner territories. A territory within the lek is defined as an area that is held and protected temporarily by a male for courtship and mating (Arita and Kaneshiro 1985). We hypothesized that spawning rates would be higher at the seaward locations that better aid the dispersal of gametes from reef to pelagic settings. In response to higher spawning rates, we hypothesized that egg predator densities during spawning and egg predation rates would also be higher for mating territories in seaward locations. Additionally, we hypothesized that spawning interruption rates would be higher in the outer reef locations as fish abandon spawning to avoid interference from higher numbers of planktivorous egg predators in the seaward locations.

\section{Materials and methods}

\section{Study site}

Apra Harbor, a deep water commercial and naval port, is situated on the western coast of the island of Guam, Mariana Islands (Fig. 1). Finger Reef lies within the harbor and runs westward along the southern shore of the harbor. The depth of Finger Reef ranges from 1 to 
$6 \mathrm{~m}$ and the benthic composition is predominantly Porites rus coral. This site is frequented by recreational divers and snorkelers, and fish feeding by both has been observed here. Gomphosus varius courts and spawns using a lek-like mating system within a spawning aggregation that occupies about $800 \mathrm{~m}^{2}$ of this location.

\section{Data collection}

Fish were not collected, killed, or harmed in any way over the course of this study. Territories of spawning male G. varius were located using snorkeling and SCUBA. An observer swam a transect along the reef and when a courting male was observed, the location of his territory was marked with a color-coded zip tie, tied to the coral, and a photo that was tagged with a GPS point. We repeated these methods until all male mating territories within Finger Reef were marked (Fig. 1) and did not conduct further surveys for new territories throughout the course of this study. Gomphosus varius displays strong sexual dimorphism where all females are grey and terminal phase males holding territories are bright blue and green. It is not known if $G$. varius has functional initial phase males with similar coloring to that of females, but we did occasionally observe transient individuals whose coloring was midway between that of a female and a male. Nevertheless, this information was not needed for our study as all observed pair spawns were between a sex-changed terminal phase male and female. We were not able to identify individuals in this study.

To ensure that the behaviors of spawning fish did not change in the presence of an observer, we placed cameras near spawning males for an hour. We compared recorded courtship behaviors, successful spawns, and egg predation to direct observations and no qualitative differences in behavior were observed. We did not identify specific individuals for our observations but rather considered that the location of the mating territory would dictate both mating success of the individuals

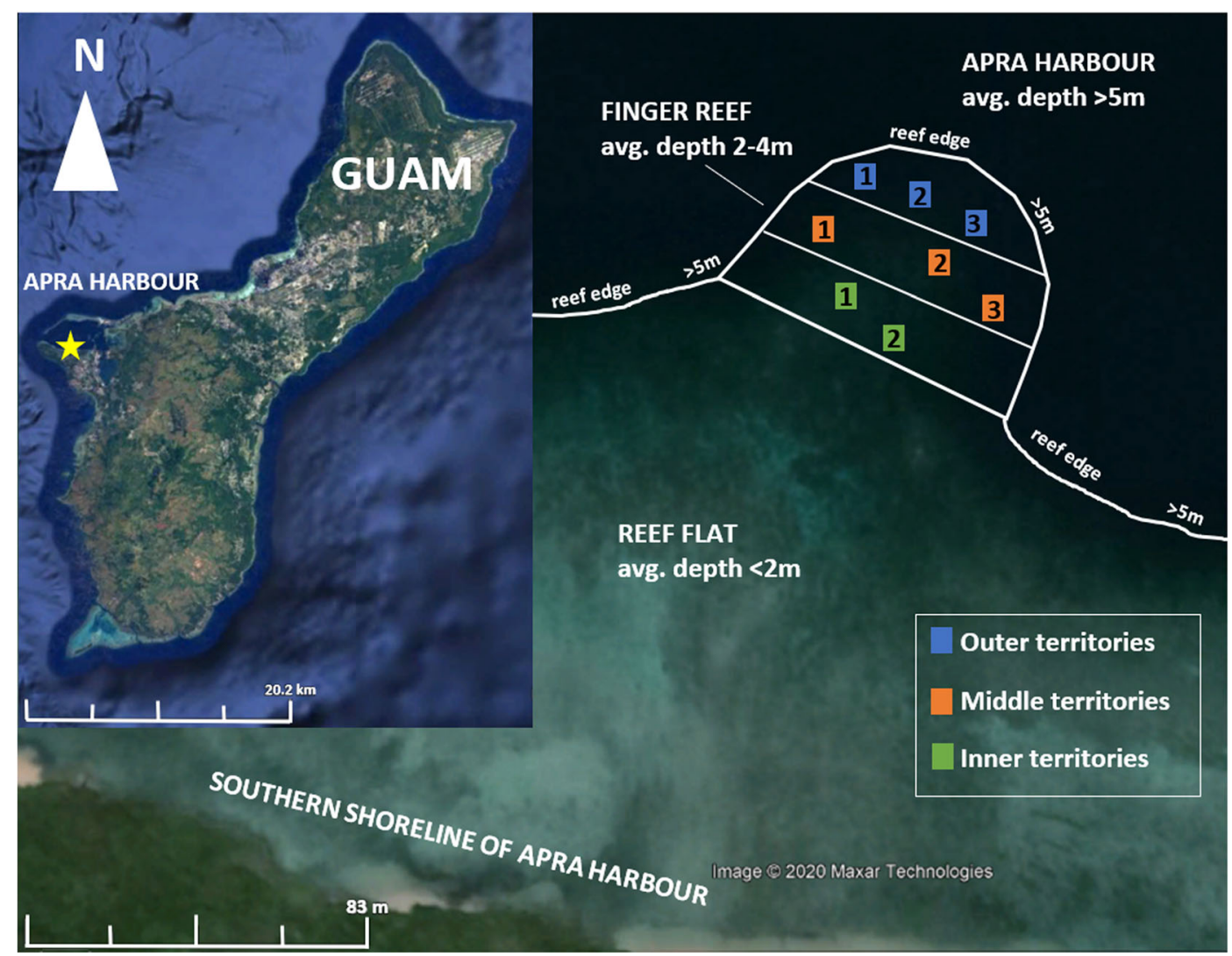

Fig. 1 Map showing the study site and mating territory locations on Finger Reef, located along the southern shore of Apra Harbor, Guam, Mariana Islands. A map of Guam is inset in the map of
Finger Reef with a star showing the location of Finger Reef. GoogleEarth Image (c)DigitalGlobe 
holding that territory and the level of egg predation attempts made there.

We found a total of eight active G. varius spawning territories on Finger Reef: three in the outer area, three in the middle area, and two in the inner area. A territory was considered active if a male was seen courting above the established territory at the beginning of spawning each day. Outer reef territories were located farthest from the shore while inner territories were located nearest the shore. We did not perform additional surveys to determine if new territories were formed over the course of the study, but none were noticed during our spawning observations. All data were collected between January 2018 and May 2018. We conducted over $36 \mathrm{~h}$ of active spawning observations, and spawning occurred on 17 of 20 observation days. Spawning occurred between 0900 and $1400 \mathrm{H}$ with the start and end time varying daily.

Each day, we randomly selected up to four territories and the behavior of the male holding each territory was observed for $30 \mathrm{~min}$. During these observations we recorded the following: 1) The number of successful spawning events. A successful spawn was defined as when a male and female complete a spawning rush that ended in the release of gamete which appear as a milky cloud in the water column. 2) The number of interrupted spawning attempts. An interrupted spawning attempt was defined as when a pair begins a spawning rush but do not complete it with the release of gametes. 3) The sex of the individual aborting the spawning attempt. The individual that turned away from the rush was identified as the individual aborting spawning. Since G. varius displays strong sexual dimorphism, males were easily distinguished from females by their bright coloring. 4) The number of egg predation events. An egg predation event was defined as when a planktivore rushed through the gamete cloud immediately after a spawning rush. 5) The species of egg predator feeding on eggs. We repeated these methods at each mating territory on four separate occasions throughout the study.

To estimate the species composition, abundance, and density of $G$. varius and the egg predators within each spawning territory, we used NOAA's Stationary Point Count (nSPC) method (based upon Bohnsack \& Bohnsack and Bannerot 1986). We performed visual fish surveys within nine stationary point count cylinders with a diameter of $10 \mathrm{~m}$ (total area $\sim 314 \mathrm{~m}^{2}$ ), with three each located within inner, middle, and outer zones of the spawning aggregation site (Fig. 1). Surveys were completed while G. varius was spawning. Since some of the mating territories were closer than $10 \mathrm{~m}$ apart, the cylinders were counted with sufficient spacing between each to avoid overlapping while still surveying the general area of the mating territories within the reef zones. We conducted counts of G. varius and the egg predators Chromis atripectoralis Welander \& Schultz 1951, Abudefduf sexfasciatus Lacepede 1801, A. vaigiensis Quoy \& Gaimard 1825, and Thalassoma hardwicke Bennett 1830 within each cylinder for a fiveminute period to assess the species present, and then for a 10-min period to estimate the abundance of each listed species, chosen based on prior observation. We did not record fish sizes. We replicated these surveys twice within each reef zone during the study period for a total of 18 survey samples.

\section{Statistical analysis}

Successful spawns and spawning interruption count data had zero-inflated, negative binomial distributions that we tested using hurdle models (Zuur et al. 2009). These models have two parts: the first describes the probability of a zero count and the second describes the expected rates of the non-zero counts. Tests of significance took both parts into account simultaneously. The idea behind a hurdle model is that for something to be observed, a hurdle must first be crossed. For an example related to this study, if said hurdle is crossed, you would see a successful spawn but if the hurdle is not crossed no successful spawns would be observed. In this model all zeros are treated the same. If there were not any spawns, or if there were but they were not seen, the count was still zero.

We used a one-way analysis of variance (ANOVA) to test for differences in densities (number of individuals per area) of planktivorous fishes between outer, middle, and inner zones, after confirming that the data fully conformed with the assumptions of ANOVA. Egg predation events were rare and could not be statistically compared between mating territory locations. Instead, we performed a linear regression model to determine the relationship between predation rates (predation events per 30-min observation period) and spawning rates (successful spawns per 30-min observation periods) after confirming that the data fully conformed with the assumptions of linear regressions. 


\section{Results}

Observational results

Prior to courtship and spawning, groups of males were observed swimming around the site together, but no male-male aggression was seen during this time. Directly before courtship and spawning began, males positioned themselves above their territories that were usually located at a prominent Porites rus coral head. At this time, males chased both planktivorous fishes and conspecific males from their territories. Females began migrating to the spawning aggregation site and chose a territory where they waited to spawn. When females arrived at a male's territory, he began courtship by swimming in circles above her and fluttering his pectoral fins until a female swam up to him to initiate a spawning rush. Spawning was occasionally interrupted by a female that initially approached the male but then abandoned the spawning rush by turning away from the male and returned to the coral head or by the male chasing away other males and planktivores. Spawning occurred when a female swam up to meet the male and the pair rapidly swam towards the surface with their bellies touching, released their gametes near the surface, and returned to the bottom. After the release of gametes, various planktivorous species sometimes rushed to the gamete cloud and consumed gametes within it. After spawning, the male continued with courtship and territorial defense. Nearly all spawns observed were paired. Only two events of streaking by other terminal phase males were observed. Streaking occurs when a second male joins the spawning pair at the apex of their spawning rush (Warner et. al 1975). There were no observations of predation attempts on spawning adults by piscivores. Occasionally during spawning hours males appeared to "herd" females from other areas of the reef into their territories. A terminal phase male was seen chasing females from the middle and inner territories towards the outer territories. However, it wasn't clear if this male was holding an outer territory and attempting to get more females into his territory or if this was just aggressive behavior. This happened only twice, and these behaviors were not formally included in the study.

Statistical results

There was a significant difference in spawning rates between mating territory locations (outer, middle, and inner) with $98.8 \%$ of spawning occurring in the outer zone territories (Fig. 2) and $90.3 \%$ of all spawning occurring solely in one outer territory (OT2) (Fig. 3). For the first part of the hurdle model (the probability of getting a zero count) the mating territory location influenced the probability of spawning occurring with the outer zone territories being significantly different from the inner and middle zone territories (z-statistics = -2.069 and -2.157 respectively, for the probability of obtaining zero counts, and $P<0.05$ for both zeroinflated hurdle comparisons between mating territory locations). For the second part of the hurdle model (the expected rates of the non-zero counts) the mating territory location did not predict the spawning rate. Within the outer zone territories (OT 1, OT 2, and OT 3), mating territory location did not influence the probability of spawning occurring (the first part of the hurdle model) but it did predict the spawning rate (the second part of the hurdle model) with OT 2 being significantly different from OT 3 (z-statistic $=-3.235$ for the difference in spawning rates where non-zero counts existed, $P<0.01$ for zero-inflated hurdle comparisons of OT 2 and OT 3).

All egg predation events occurred in one outer territory (OT 2). Egg predation was minimal during the study period, however, and it occurred after only $8.2 \%$ of all spawns (Figs. 2 and 3). Egg predation rates were positively and linearly correlated with spawning rates (Fig. 4, $\mathrm{R}^{2}=0.6115, \mathrm{P}<0.05$ ). Furthermore, there was no significant difference in the densities of egg predators across mating territory locations (Figs. 5 and 6, F-statistic $=0.781, P=$ 0.476, one-way ANOVA).

There was a significant difference in both male and female spawning interruption rates between mating territory locations (Fig. 7). For females, the mating territory location did not influence the probability of female spawning abandonment occurring (the first part of the hurdle model). However, it did predict the rate of abandonment (the second part of the hurdle model) with the inner zone territories being significantly different from the middle and outer zone territories (z-statistic = -5.007 and -4.528 , respectively for the difference in spawning rates where non-zero counts existed, and $P<0.001$ for both zero-inflated hurdle comparisons of mating territory locations). For males, mating territory location influenced the probability of male spawning abandonment occurring (the first 
Fig. 2 Spawning and predation rates across temporary mating territory locations of Gomphosus varius. Most spawning events and all predation occurred in the outer mating territories $(P<0.05)$
Spawning and predation rates across mating territory location

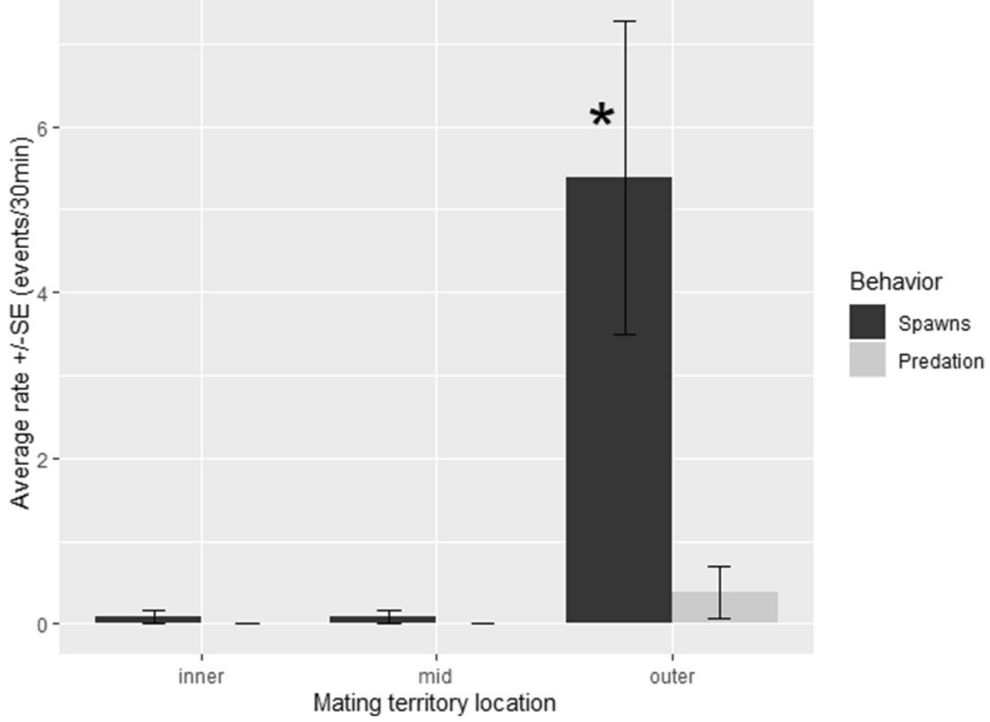

part of the hurdle model) with the inner zone territories being significantly different from those in the middle zone (z-statistic $=-2.289$ for the probability of obtaining zero counts, and $P<0.01$ for zero-inflated hurdle comparisons between mating territory locations). Mating territory location, however, did not predict the rate of male spawning abandonment (the second part of the hurdle model).

\section{Discussion}

Males in the outer zone territories were predicted to have higher spawning rates and our results support this. Only one spawning event was seen in each of the middle and inner territories. The days in which these spawns were observed were particularly busy spawning days for G. varius, as well as many other wrasse species that spawn at Finger Reef. Females may become less
Fig. 3 Spawning and predation rates across outer temporary mating territories of Gomphosus varius. Most spawning events and all predation occurred in outer temporary mating territory 2 $(P<0.01)$

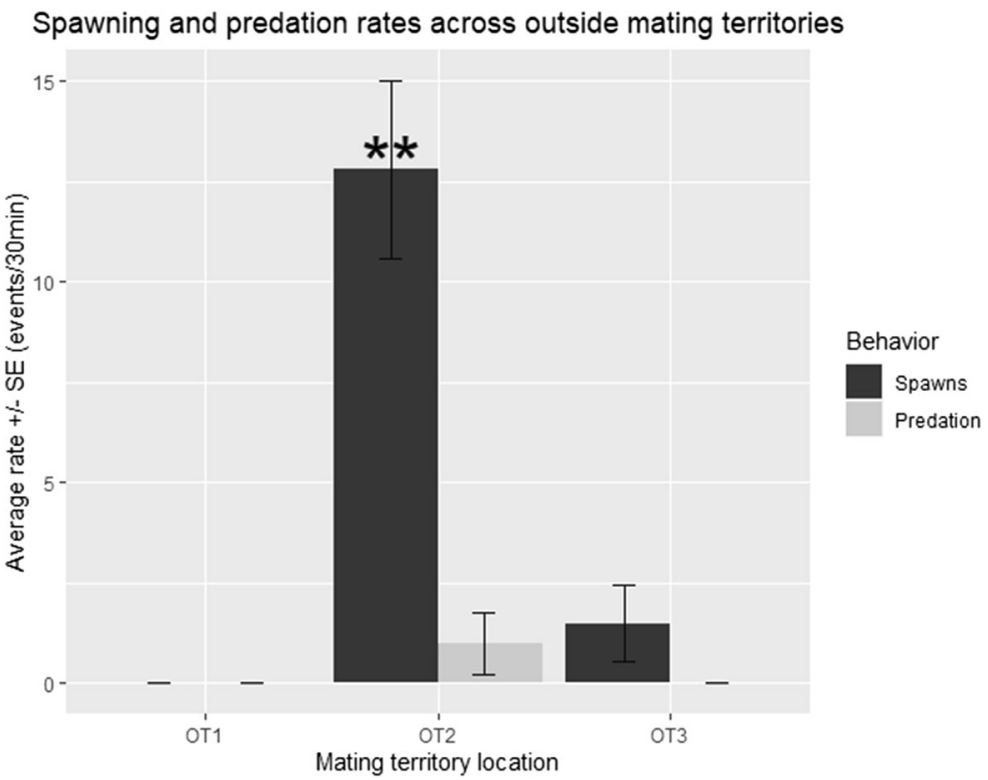


Fig. 4 Linear regression between egg predation rates and spawning rates of Gomphosus varius $(\mathrm{P}<$ $0.05)$. Shaded area indicates a 95\% confidence interval

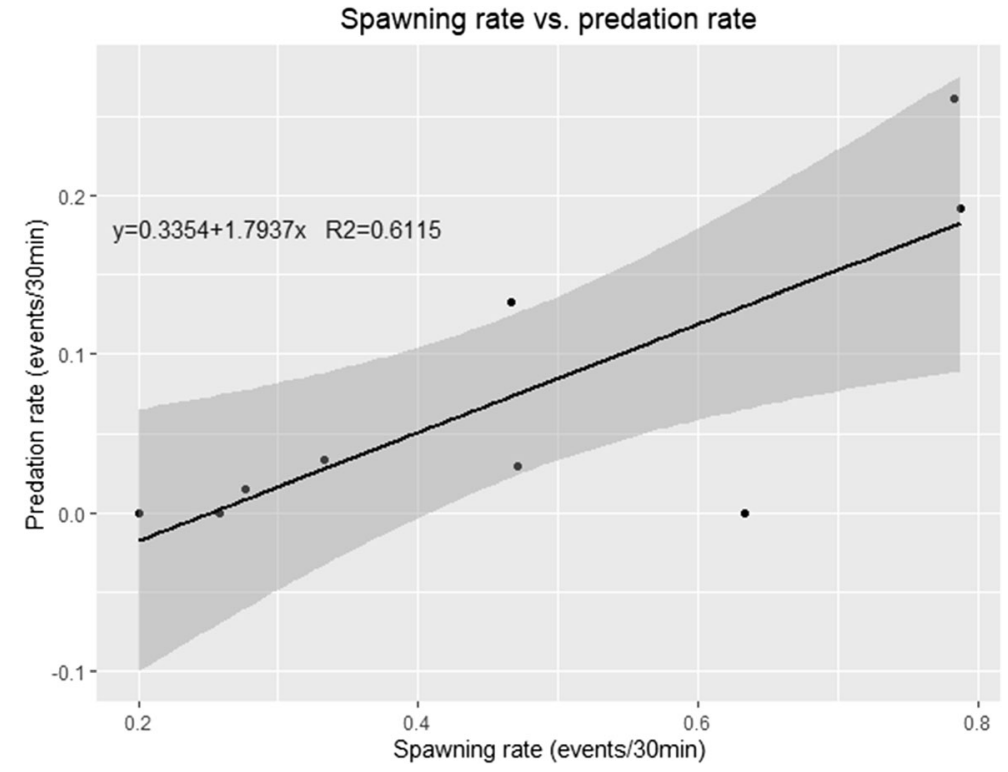

selective in their mates when the wait time increases for spawning with a more desirable male, as fertilization success tends to decrease with time after ovulation (Kuwamura et al. 2016). More data needs to be collected to find a peak spawning time and to determine if there is a correlation between it and the spawning rates found in the middle and inner zone mating territories. Additionally, males that were positioned in the more successful outer zone territories for the day remained there for the entirety of spawning, but males positioned in the inner and middle zone territories did not remain within a single territory and it was unclear if territory possession changed throughout the day. Fiske et al. (1998) found that territory attendance (the time a male spent at their territory) was most highly correlated with male mating success. At Finger Reef, females may use attendance as a signal when choosing a mate. During several observation periods, females observed waiting at inner or middle territories left due to the absence of males.

Nearly all of the spawning was done at a single territory (OT 2), which is not uncommon in lekking
Fig. 5 Densities of planktivores across temporary mating locations of Gomphosus varius on Finger Reef, Guam

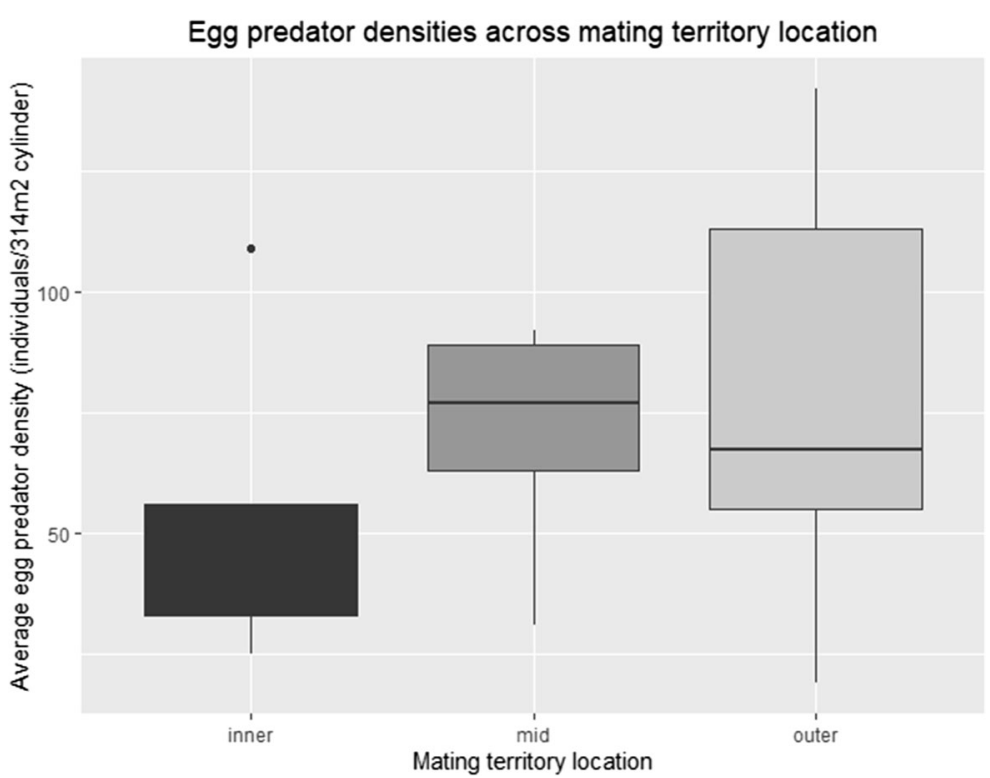


Fig. 6 Species specific distribution of planktivores and Gomphosus varius across temporary mating territory locations on Finger Reef, Guam. The species observed were as follows: Thalassoma hardwicke (Thha), Abudefduf sexfasciatus (Abse), A. vaigiensis (Abva), Chromis atripectoralis (Chat), and Gomphosus varius (Gova)
Species specific distribution across mating territory location

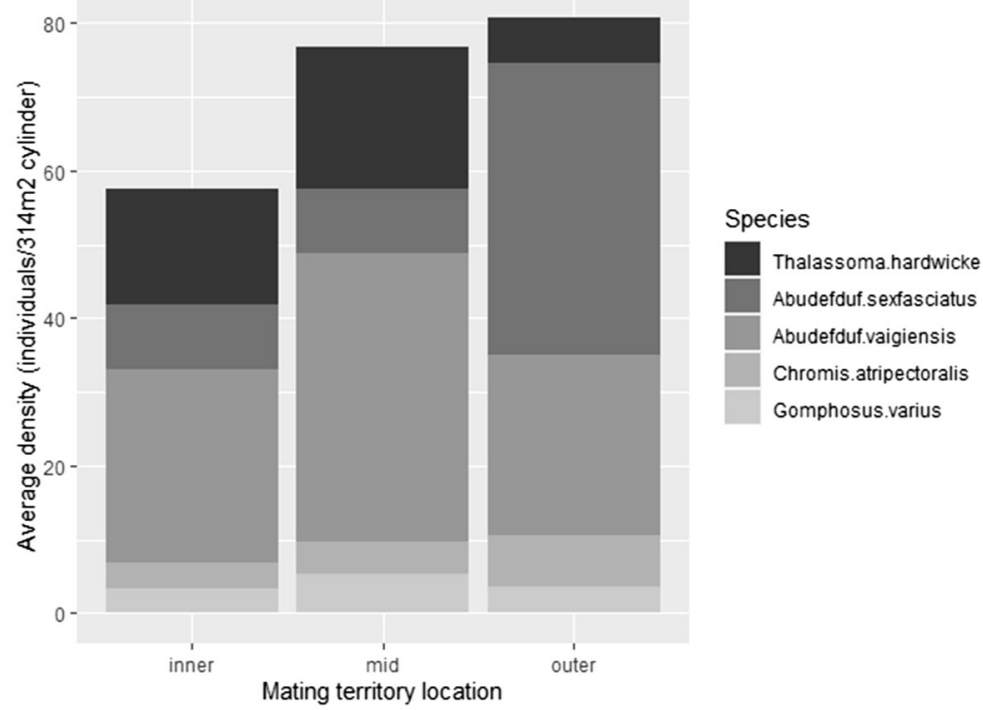

species across all taxa (Emlen and Oring 1977; Moyer and Yogo 1982; Arita and Kaneshiro 1985; Kirkpatrick and Ryan 1991; McDonald and Potts 1994; Petrie et al. 1999; Sherman 1999; Duraes et al. 2009). The reason for this highly-skewed success is not well understood but it has been hypothesized that males in a lek are kin or that there is a hierarchal system in leks (Sherman 1999). It would be useful to track territory possession and to collect genetic data to determine whether there is a hierarchy in place or if lekking males are kin, a possibility that seems doubtful given the life history strategies of pelagic spawning and larval dispersal (Hamner and Largier 2012). The presence of a hierarchy system at the spawning aggregation site is more likely. Males were often observed swimming side-by-side in small groups. Males may be using this lateral display behavior to size each other up and determining territory ownership for the day (Oliveira and Almada 1998). Another factor driving the success of the male at OT 2 is that most successful males have often been found to be positioned in the center of leks (Fiske et al. 1998), and OT 2 is positioned between OT 1 and OT 3. This central
Fig. 7 Male and female spawning interruption rates across temporary mating territory locations of Gomphosus varius. The rates of interruption in the inner territories were significantly different from the middle and outer territories for both males and females $(\mathrm{P}<0.01$ and $P<0.001$ respectively)

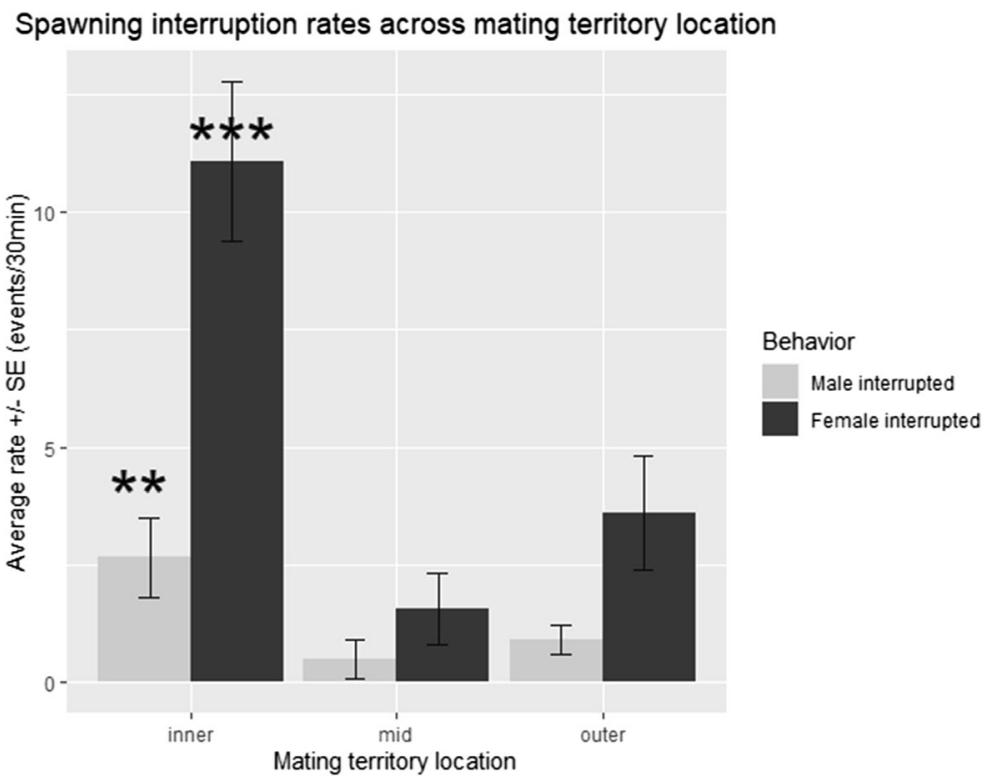


position along the edge of the reef may offer extra protection for the spawning individuals and their gametes, thus making it a more desirable spawning location. OT 2, however, was the only one that experienced gamete predation, so this does not hold true for egg predation.

Egg predation rates were predicted to be higher in the outer territories. Every predation event occurred in the outer territories therefore we were unable to compare zeroes and the data did not allow for a meaningful comparison. Most gamete predation events were by a single terminal phase $T$. hardwicke male who held a mating territory in the same location as OT 2 and usually was already in the area and could feed on eggs intermittently. There was only one instance where a group of Abudefduf sexfasciatus and A. vaigiensis swarmed the recently spawned gametes of $G$. varius. Kuwamura et al. (2016) found that $G$. varius was often aggressive towards $T$. hardwicke as well as damselfishes during spawning and that while predation events were rare, T. hardwicke occasionally attacked the eggs of $G$. varius. Additionally, predation rates were found to increase as spawning rates increased. This outcome is likely given that spawning events are obvious, and they quickly draw the attention of egg predators. Therefore, when spawning occurs frequently, the probability of egg predators encountering eggs may be higher. Spawning is known to draw the attention of predators and many observations of spawning fish have noted the presence of planktivores; however, egg predation rates greatly vary across locations and species based upon the availability of other planktonic food or how busy an aggregation site is on a given day (Johannes 1978; Colin and Clavijo 1988; Colin and Bell 1991; Claydon 2004). Interestingly, Colin and Bell (1991) didn't observe predation on $G$. varius gametes during spawning at Enewetak, Marshall Islands. So, why does predation occur only in some systems or locations? Could fish feeding by tourists at Finger Reef, which attracts various species of fishes, including planktivores, be related to this? The identification of similar G. varius spawning aggregation sites at Guam that do not have fish feeding would provide an opportunity to compare egg predation rates between the two sites.

Planktivore densities were predicted to be highest in the outer zone territories during the spawning period. While the outer zone territories had higher densities of planktivores, the difference was not significant. Planktivorous fish densities tend to be higher in deeper waters near reef edges that provide more plankton (Hobson and Chess 1978; Thresher and Colin 1986; Friedlander et al. 2010). The even distribution of planktivores at Finger reef is likely due to the amount of group spawning by other species that occurs closer to the middle zone territories of G. varius. The majority of planktivores on Finger Reef were the damselfishes A. sexfasciatus and A. vaigiensis and were often seen consuming the eggs of group spawning T. hardwicke. Thalassoma hardwicke also had high densities at Finger Reef, which is most likely because they also have a spawning aggregation at this site. A comparison of planktivore densities across various spawning aggregation sites of $G$. varius or other wrasse species would be interesting to see if this pattern is common.

Outer zone spawning territories were predicted to experience higher spawning interruption rates. We thought that the increased threat of egg predation would result in more cautious spawning, but our results did not support this hypothesis. Instead, spawning interruptions primarily occurred from direct interactions between bird wrasses, not with egg predators. The higher numbers of bird wrasse males in the inner zones of the spawning aggregation site led to increased intraspecific competition for females and territories. Sometimes multiple males would try to court a single female, and this often led to an altercation between rival males that interrupted spawning. Spawning interruptions by both females and males in the outer zone territories appeared to be more often associated with encroaching planktivores rather than due to conspecifics but occurred less frequently than intraspecific interruptions. It was sometimes difficult, however, to discern the reason for spawning interruption and more data should be collected to confirm these observations.

Spawning aggregations provide an efficient way for fishes to increase their reproductive success. They also have social and economic importance from a fisheries management perspective (Sadovy de Mitcheson and Erisman 2012.) Little is known about the characteristics and dynamics of the spawning aggregations of many species, thus making it important that we increase our understanding of these reproductive systems. Recognizing the role that spawning locations and egg predation pressures play in spawning success can help better inform fisheries management decisions. Protecting spawning aggregations sites, especially those that host multiple species, can benefit the entire ecosystem and sustain complex food webs (Erisman et al. 2017). The 
family Labridae has a considerable number of species that form resident spawning aggregations, (Colin and Bell 1991) some of which use a lek-like mating system within an aggregation (Desvignes et al. 2017). This study provides insight into the influence that reef location has on a spawning aggregation with a lek-like mating system of $G$. varius at Finger Reef. This species is observed easily and serves as an excellent model species to further our understanding of reproductive behavior and spawning aggregation dynamics.

Acknowledgments We would like to thank C. Te Beest, M. Kelokelo, K. Ebeling-Whited, V. Moscato, and C. Starsnic of the University of Guam Marine Laboratory (UOGML) for field work assistance. We would also like to thank Dr. P. Houk and Dr. A. Kerr (UOGML) for assistance with statistical analyses. Thanks to T. Summers of the U.S. Naval Facilities Engineering CommandGuam for sponsorship onto Naval Base Guam. This project was supported by the U.S. National Science Foundation-Established Program to Stimulate Competitive Research (EPSCoR) under Grant Number OIA-1457769. Any opinions, findings, and conclusions or recommendations expressed in this material are those of the author(s) and do not necessarily reflect the views of the National Science Foundation.

Availability of data and material The datasets generated during and/or analyzed during the current study are available from the corresponding author on reasonable request.

Code availability The code generated for this study is available from the corresponding author on reasonable request.

\section{Authors' contributions}

A. M. G. ideas, data generation, data analysis, manuscript preparation, funding.

E. C. F. ideas, manuscript preparation.

T. J. D. ideas, data generation, manuscript preparation, funding.

Funding Financial support was provided by a grant from the U.S. National Science Foundation-Established Program to Stimulate Competitive Research (EPSCoR) to the University of Guam (Grant Number OIA-1457769, T.J. Donaldson, Principal Investigator).

\section{Declarations}

Ethics approval Fish were not collected, killed, distressed, or harmed in any way over the course of this study. This research was strictly observational, and no approval of research ethics committees was required to accomplish the goals of this study.

\section{Consent to participate N/A}

Consent for publication The authors give the publisher permission to publish our work.
Conflict of interest The authors have no conflicts of interest to declare that are relevant to the content of this article.

Open Access This article is licensed under a Creative Commons Attribution 4.0 International License, which permits use, sharing, adaptation, distribution and reproduction in any medium or format, as long as you give appropriate credit to the original author(s) and the source, provide a link to the Creative Commons licence, and indicate if changes were made. The images or other third party material in this article are included in the article's Creative Commons licence, unless indicated otherwise in a credit line to the material. If material is not included in the article's Creative Commons licence and your intended use is not permitted by statutory regulation or exceeds the permitted use, you will need to obtain permission directly from the copyright holder. To view a copy of this licence, visit http://creativecommons.org/licenses/by/4.0/.

\section{References}

Arita LH, Kaneshiro KY (1985) The dynamics of the lek system and mating success in males of the Mediterranean fruit fly, Ceratitis capitata (Wiedemann). Proceedings of the Hawaiian Entomological Society, 25, 39-48

Bohnsack JA, Bannerot SP (1986) A stationary visual census technique for quantitatively assessing community structure of coral reef fishes. NOAA Technical Report NMFS, 41, 15

Claydon J (2004) Spawning aggregations of coral reef fishes: characteristics, hypotheses, threats and management. Oceanogr Mar Biol 42:265-302

Chop KA (2008) Lek-like behavior of the parrotfish, Chlorurus sordidus (Labridae: Scarinae), on a resident spawning aggregation site at Guam, Mariana Islands (M.S. Thesis in Biology, University of Guam, Mangilao, Guam, USA)

Colin PL, Clavijo IE (1988) Spawning activity of fishes producing pelagic eggs on a shelf edge coral reef, southwestern Puerto Rico. Bull Mar Sci 43:249-279

Colin PL, Bell LJ (1991) Aspects of the spawning of labrid and scarid fishes (Pisces: Labroidei) at Enewetak atoll, Marshall Islands with notes on other families. Environ Biol Fish 31: 229-260

Desvignes T, Bourjon P, Chanet B (2017) Reproductive behavior of the green birdmouth wrasse Gomphosus caeruleus on a Reunion Island reef: mode of reproduction, environmental factors and reproductive strategy alternation. C.R. Biologies 341:43-60

Domeier ML (2012) Revisiting spawning aggregations: definitions and challenges. In: Sadovy de Mitcheson Y, Colin PL (eds) Reef fish spawning aggregations: biology, research and management. Springer, New York, pp 1-20

Domeier ML, Colin PL (1997) Tropical reef fish spawning aggregations: defined and reviewed. Bull Mar Sci 60:698-726

Donaldson TJ (1990) Lek-like courtship by males and multiple spawnings by females of Synodus dermatogenys (Synodontidae). Japanese Journal of Ichthyology 37:292301 
Duraes R, Loiselle BA, Parker PG, Blake JG (2009) Female mate choice across spatial scales: influence of lek and male attributes on mating success of blue-crowned manakins. Proc Royal Soc 276:1875-1881

Emlen ST, Oring LW (1977) Ecology, sexual selection, and the evolution of mating systems. Science 197:215-223

Erisman B, Heyman W, Shinichi K, Ezer T, Pittman S, AburtoOropeza O, Nemeth RS (2017) Fish spawning aggregations: where well-placed management actions can yield big benefits for fisheries and conservation. Fish Fish 18(1):128-144

Fiske P, Rintamäki PT, Karvonen E (1998) Mating success in lekking males: a meta-analysis. Behav Ecol 9:328-338

Friedlander AM, Stuart AS, DeMartini EE, Sala E (2010) Spatial patterns of the structure of reef fish assemblages at a pristine atoll in the Central Pacific. Mar Ecol Prog Ser 410:219-231

Gladstone W (1994) Lek-like spawning, parental care and mating periodicity of the triggerfish Pseudobalistes flavimarginatus (Balistidae). Environ Biol Fish 39:249-257

Hamner WM, Largier JL (2012) Oceanography of the planktonic stages of aggregation spawning reef fishes. In: Sadovy de Mitcheson Y, Colin PL (eds) Reef fish spawning aggregations: biology, research and management. Springer, New York, pp 159-190

Hobson ES, Chess JR (1978) Trophic relationships among fishes and plankton in the lagoon at Enewetak atoll, Marshall Islands. Fish Bull 76:133-153

Hunter, J. 1981. Feeding ecology and predation of marine fish larvae. Pages 33-77 in R. Lasker, ed. marine fish larvae: morphology, ecology, and relation to fisheries. Seattle: Washington Sea Grant program

Johannes RE (1978) Reproductive strategies of coastal marine fishes in the tropics. Environ Biol Fish 3:65-84

Kirkpatrick M, Ryan MJ (1991) The evolution of mating preferences and the paradox of the lek. Nature 350:33-38

Kuwamura T, Suzuki S, Kadota T (2016) Interspecific variation in the spawning time of labrid fish on a fringing reef at Iriomote Island, Okinawa. Ichthyol Res 63:460-469

Loiselle PV, Barlow GW (1978) Do fishes lek like birds? In: Reese ES, Lighter FJ (eds) Contrasts in behavior. Wiley Interscience, New York, pp 33-75

McDonald D, Potts W (1994) Cooperative display and relatedness among males in a lek-mating bird. Science 266:1030-1032

Molloy PP, Cote IM, Reynolds JD (2012) Why spawn in aggregations? In: Sadovy de Mitcheson Y, Colin PL (eds) Reef fish spawning aggregations: biology, research and management. Springer, New York, pp 57-83

Moyer JT, Yogo Y (1982) The lek-like mating system of Halichoeres melanochir (Pisces: Labridae) at Miyake-jima, Japan. Ethology 60:209-226

Oliveira R f, Almada VC (1998) Mating tactics and male-male courtship in the lek-breeding cichlid Oreochromis mossambicus. J Fish Biol 52:1115-1129

Petrie M, Krupa AP, Burke T (1999) Peacocks lek with relative even in the absence of social and environmental cues. Nature 401:155-157

Robertson DR, Hoffman SG (1977) The roles of female mate choice and predation in the mating systems of some tropical labroid fishes. Ethology, 45, 298-320.Russell, M.W., Luckhurst, B. E., and Lindeman, K. C. 2012. Management of spawning aggregations. In: Sadovy de Mitcheson Y, Colin PL (eds) Reef fish spawning aggregations: biology, research and management. Springer, New York, pp 371-404

Sadovy de Mitcheson Y, Cornish A, Domeier M, Colin PL, Russell M, Lindeman KC (2008) A global baseline for spawning aggregations of reef fishes. Conserv Biol 22: $1233-1244$

Sadovy de Mitcheson Y, Erisman B (2012) Fishery and biological implications of fishing spawning aggregations, and the social and economic importance of aggregating fishes. In: Sadovy de Mitcheson Y, Colin PL (eds) Reef fish spawning aggregations: biology, research and management. Springer, New York, pp 225-284

Sherman PW (1999) Birds of a feather lek together. Nature 401: $119-120$

Thresher RE (1984) Reproduction in reef fishes. TFH Publications, Neptune City

Thresher RE, Colin PL (1986) Trophic structure, diversity and abundance of fishes of the deep reef (30-300m) at Enewetak, Marshall Islands. Bull Mar Sci 38:253-272

Warner RR, Robertson DR, Leigh EG (1975) Sex change and sexual selection. Science 190(4215):633-638

Zuur A, Ieno EN, Walker N, Saveliev AA, Smith GM (2009) Mixed effects models and extensions in ecology with R (pp. 271-274). New York: Springer

Publisher's note Springer Nature remains neutral with regard to jurisdictional claims in published maps and institutional affiliations. 